\title{
Arqueología de la esclavitud africana en la frontera uruguayo-brasileña: el caso de la Estancia de los Correa (Rocha, Uruguay)
}

\section{Resumen}

En Uruguay existen comunidades de personas descendientes de esclavos africanos (siglos XVIII y XIX) que presentan condiciones sociales y económicas estructuralmente desfavorables. Además de la pobreza y la discriminación, estas comunidades han sido excluidas de los relatos sobre el proceso de construcción nacional. Se ignora el rol que estas comunidades han tenido en el desarrollo histórico, territorial y de la matriz productiva rural. Este trabajo se centra en visibilizar el rol de la mano de obra esclava en los primeros desarrollos ganaderos del país. Se localizó, identificó y contextualizó arqueológicamente el mayor latifundio colonial de la frontera este entre Uruguay y Brasil. Se pudieron identificar y registrar "cascos de estancias", cementerios y diferentes estructuras en piedra (corrales, cercos, mangueras, etc.) así como diferentes indicios del trabajo de los esclavos. La reconstrucción arqueológica de la esclavitud resultó además un camino apropiado para actualizar la historia local y reposicionar a los esclavos en la memoria de sus descendientes.

\section{Archaeology of African slavery on the Uruguayan-Brazilian border: The case of "Estancia de los Correa" (Rocha, Uruguay)}

\footnotetext{
Abstract

In Uruguay, there are communities of African slaves' descendants (18th and 19th centuries) that present unfavorable structural social and economic conditions. In addition to poverty and discrimination, these communities have been excluded from the narratives of the nation-building process. However, they have played a fundamental role in the historical development of the national rural productive matrix. Within the livestock

* Departamento de Arqueología, Facultad de Humanidades y Ciencias de la Educación, Centro Universitario de la Región Este (CURE), Universidad de la República - Sistema Nacional de Investigadores, Agencia Nacional de Investigación e Innovación del Uruguay (ANII). Av. Uruguay 1695 (CP 11200), Montevideo, Uruguay. E-mail: lopezmazz@yahoo.com.ar

** Departamento de Ciencias Sociales y Humanas, Centro Universitario de la Región Este (CURE), Universidad de la República - Sistema Nacional de Investigadores, Agencia Nacional de Investigación e Innovación del Uruguay (ANII). Ruta Nacional №9 intersección con ruta №15 (27000), Rocha, Uruguay. E-mail: carlos.marin@cure.edu.uy *** Departamento de Sistemas Agrarios y Paisajes Culturales, Centro Universitario de la Región Este (CURE), Universidad de la República - Sistema Nacional de Investigadores, Agencia Nacional de Investigación e Innovación del Uruguay (ANII). Ruta Nacional №9 intersección con ruta №15 (27000), Rocha, Uruguay. E-mail: jmdabezies@cure.edu.uy **** Instituto de Ciencias del Patrimonio (INCIPIT), Consejo Superior de Investigaciones Científicas (CSIC), Av. de Vigo s/n (CP 15705) Santiago de Compostela, A Coruña, España. E-mail: carlos.tejerizo-garcia@incipit.csic.es
}

\section{Palabras clave}

Esclavitud Ganadería histórica Arqueología Frontera

Keywords

Slavery

Historical livestock Archaeology

Border 
development, the role that the slaves have played is not part of the official historical narrative. This work focuses on making visible the role of the slave workforce in the first livestock developments in the country. The largest colonial farm of the southern border between Uruguay and Brazil was located, identified, and archaeologically contextualized. We identified and registered "historical farms", cemeteries, and different structures in stone (corrals, fences, pens, etc.), as well as different places were the slaves worked. The archaeological reconstruction of slavery was an appropriate way to update local history, repositioning the slaves in the memory of their descendants.

\section{Introducción}

Los estudios sobre la diáspora africana en América del Sur han tenido particular desarrollo en los últimos años. Por un lado, buscan compensar la gran ausencia de las comunidades africanas en los relatos históricos nacionales. Por otro lado, los estudios actuales asumen que el objeto de estudio - los esclavos africanos y sus descendientes-, son un sujeto histórico con derechos sociales. Contingentes de africanos fueron usados intensamente como mano de obra en trabajos coactivos, como combustible humano de las guerras regionales y civiles, y jugaron un rol decisivo en la construcción de las naciones.

El reconocimiento de los derechos civiles de los afrodescendientes ha sido un largo proceso vinculado a la descolonización de los países americanos. A veces la dialéctica social interna de los países marcó el proceso de revisión histórica. Otras veces ha sido la legislación internacional la que ha impuesto a los estados políticas de reconocimiento de derechos y de discriminación positiva. En Uruguay este proceso ha estado dinamizado por ambas vías. Las crisis políticas de los últimos 50 años en Uruguay han cuestionado fuertemente algunos estereotipos identitarios propios de una sociedad esencialmente europea y han marcado el inicio de un proceso de revisión histórica entre descendientes de los pueblos indígenas y africanos (López Mazz, 2018).

La zona del este de Uruguay fronteriza con Brasil ha sido objeto de importantes investigaciones históricas (Borucki, Chagas y Stalla, 2009, 2012) sobre la esclavitud en el siglo XIX. Además, cuenta con algunos elementos patrimoniales incorporados a la "Ruta del Esclavo. Resistencia, Libertad y Patrimonio" de la UNESCO, desde el año 2009, como el Casco de Estancia del Oratorio de los Correa, el poblado abandonado de Portera Negra y el Club Social Ansina de la ciudad de Castillos (Frega, 2010).

1. “Construcción participativa de la memoria de las comunidades afro descendientes de la frontera uruguayo-brasilera", proyecto financiado por la

Comisión Sectorial de Extensión y Actividades en el Medio de la Universidad de la República del Uruguay, en colaboración con el club de afrodescendientes Club Social Ansina (Castillos,

Rocha) y con la Usina Cultural de Castillos (Rocha) del Ministerio de Educación y Cultura. En este trabajo presentaremos, los primeros resultados arqueológicos, dejando para otro estudio monográfico los principales resultados de las entrevistas antropológicas.
Este trabajo se centró en la generación de conocimiento sobre las comunidades de origen africano del periodo de esclavitud en la región (siglos XVIII y XIX). Se trató de localizar, identificar y registrar una materialidad arqueológica que se pudiera contrastar con la memoria oral y la documentación escrita ${ }^{1}$. La unidad de análisis espacial seleccionada para la investigación arqueológica es el perímetro original de la Estancia de los Correa, el mayor latifundio del Departamento de Rocha y que más esclavos tuvo trabajando durante el siglo XIX.

Los documentos disponibles para analizar la esclavitud durante el siglo XIX son declaraciones judiciales, escrituras, padrones, inventarios y testamentos que, si bien permiten cuantificar información histórica de indudable valor, no permiten analizar en detalle las labores realizadas por los esclavos, las relaciones que mantenían entre sí, ni conocer sus valores culturales (Borucki et al., 2009). Consideramos que mediante el análisis de las materialidades y espacialidades que mediaron en los trabajos domésticos y agropecuarios de los esclavos podemos ayudar a identificar y caracterizar alguno 
de los diferentes tipos de trabajos que realizaron, revalorizar el lugar que ocupaban en la organización económica, entender la movilidad y aproximarnos un poco a las formas de vida. La documentación y estudio de este paisaje cultural permite caracterizar a la materialidad que hace visible la esclavitud en tanto foco o huella de memoria (Criado-Boado, 2001). En ese sentido, la Estancia de los Correa puede recuperar su lugar histórico en la memoria de los afrodescendientes de Rocha.

Este artículo expone los resultados de una investigación que buscó localizar y registrar testimonios de las comunidades esclavas de origen africano, a través de la identificación del correlato material más conspicuo, que como lo sugieren algunas fuentes históricas y orales (VVAA, 1966) fue la construcción de muros en piedra canteada para diferentes infraestructuras ganaderas.

\section{El este de Uruguay en el contexto histórico regional: el ganado y la frontera}

La Banda Oriental del río Uruguay fue una de las últimas zonas de América en ser colonizada. Si bien el Tratado de Tordesillas de 1494, la situaba bajo el dominio español, no fue hasta que Portugal funde en 1680 la Nova Colonia do Santíssimo Sacramento (Colonia de Sacramento, Uruguay) que el imperio español fijó sus ojos en este territorio. El hostigamiento de los bandeirantes paulistas sobre las misiones jesuíticas provocó destrucciones y mucho ganado vacuno se escapó, se expandió y se reprodujo de forma prolifica.

La respuesta española para afianzar la Banda Oriental fue la fundación de Santiago y San Felipe de Montevideo (entre 1724 y 1730 con mano de obra guaraní). Con estos movimientos políticos la laxa y discutida frontera imperial se fue acotando y dejó a la actual región este de Uruguay en el centro de las disputas. Portugal tratará también de afianzar su presencia erigiendo en 1737 el presidio de Jesús María José (origen de la actual Río Grande do Sul), al tiempo que se apoderó del Fuerte de San Miguel, ubicado seis kilómetros al sur de la Laguna Merín. Por el Tratado de Madrid (1750) se cedió a Portugal buena parte de este sector y los pueblos jesuíticos de la margen izquierda del río Uruguay.

La anulación del Tratado de Madrid en 1762 alentó los reclamos del Gobernador de Buenos Aires, Pedro Antonio de Cevallos para que Portugal devolviera los territorios españoles ocupados y recuperó para España la Colonia del Sacramento, la Fortaleza de Santa Teresa, el Fuerte de San Miguel y el Fuerte de Jesús María José. El Tratado de San Ildefonso (1777) fijaría grosso modo la frontera entre ambos Imperios en el arroyo Chuy, la laguna Merín y la cabecera del río Negro hacia el norte. Ana Inés Moraes (2005) critica la historiografía que trata este proceso y remarca la necesidad de un cambio en la visión espacial promovida por los discursos articulados desde los centros de poder como Montevideo y Buenos Aires, ya que naturalizan los actuales límites de los Estados-nación. También aboga por un giro étnico, pues pareciera que el avance de ambos imperios sobre la franja en disputa se realizara sobre un vacío demográfico. En coincidencia con esta postura, investigaciones recientes promueven nuevas miradas sobre la frontera, en donde los indígenas pasan a ser protagonistas del relato histórico (Erbig, 2015).

Fueron los caciques güenoa-minuanes desde el siglo XVII, los primeros ganaderos de caballos, de vacas y de mulas de la Banda Oriental. Comerciaban con los jesuitas en el río Uruguay, con los portugueses de Río Grande do Sul, los españoles de Buenos Aires, así como con piratas holandeses y franceses (Barrios Pintos, 2013; Martins Farias, 2013). La riqueza ganadera gestionada por estos caciques indígenas fue de gran magnitud. 
En 1705 bajaron desde los pueblos misioneros dos curas jesuitas y mil indios tapes (guaraníes) a negociar con los caciques güenoas-minuanes de la zona de Valizas (actual Departamento de Rocha, Uruguay) la mayor tropeada registrada en la historia, la venta de unas 420.000 cabezas de ganado a cambio de yerba mate, alcohol, tabaco y mantas (Barrios Pintos, 1967; Perdomo, 2012).

El control del ganado y el control de la frontera pautan un proceso progresivo de ocupación europea del territorio, con sucesivos ajustes políticos, militares y económicos. Este proceso histórico no ocurrirá sobre un espacio vacío como sugiere la historiografía clásica, sino que por el contrario estará marcado por un intenso relacionamiento interétnico en el que sobresale a partir de fin del siglo XVIII, el comienzo del empleo intensivo de mano de obra esclava. De acuerdo a los archivos para el periodo 1765-1825 los contingentes de esclavos llegados a la zona a través del tráfico portugués provenían en su mayoría (71\%) de África Centro-Oeste (Congo, Angola), así como de África Occidental (26\%) (Mina, Guinea, Cabo Verde) y África Oriental (3\%) (Mozambique) (Osório, 2004, p. 12).

\section{Metodología}

El tema de investigación de este trabajo es la reconstrucción histórico-arqueológica de un latifundio esclavista colonial. Esta aproximación interdisciplinaria se realiza en el marco de una arqueología histórica que reconoce similar y complementario peso fáctico a la evidencia documental y material (South, 1977). La reciprocidad de perspectivas entre un registro consciente y deliberado del documento y la naturaleza inconsciente de la cultura material (Andrade Lima, 1989) auguran un conocimiento más robusto y documentado a una serie de temas vinculados a la vida y el trabajo de las comunidades esclavas del este de Uruguay durante el periodo colonial.

Por un lado, en base a la información histórica (documental y oral) procedimos a caracterizar la estructura (áreas especializadas, organización espacial) y la dinámica (social y productiva) del asentamiento esclavista de los Correa. Se analizaron trabajos históricos de corte académico, así como otros producidos por historiadores locales que recogen antiguas tradiciones orales. Se buscó identificar lugares y productos materiales asociados a la evolución histórica de las comunidades esclavas en la región. En una primera etapa la investigación arqueológica partió de mapas históricos que fueron analizados superponiendo imágenes satelitales para identificar en el terreno actual los límites y características de las antiguas propiedades. De este modo se construyó una hoja de ruta con los diferentes elementos identificados, que sirvió de guía al trabajo de observación directa sobre el terreno mediante una prospección arqueológica intensiva.

Por otro lado, y en base a la información histórica se realizaron diferentes trabajos de campo. El relevamiento arqueológico se centró en la Estancia Oratorio de los Correa y áreas inmediatas de las estancias limítrofes. El trabajo en el terreno consistió en identificar, describir, fotografiar, mapear y georreferenciar de cara a generar un Sistema de Información Geográfica el variado elenco de estructuras: cascos de estancia y galpones vinculados (tanto los realizados en piedra como en ladrillo, aparte de los más modernos levantados a lo largo del siglo XX), cierres ganaderos (cierres vegetales con flora autóctona, donde destacan los corrales de palma Butia odorata, mangueras de piedra y corrales circulares de piedra), canteras para extraer materia prima, y cementerios. En el campo se llenaron fichas con detalles constructivos de las estructuras y se efectuaron observaciones sobre posibles cronologías relativas entre las estructuras (relaciones estratigráficas). También se realizó una excavación arqueológica estratigráfica en un cementerio, con el fin de reconocer los patrones funerarios, pero sin realizar exhumaciones. 
Esta aproximación histórico arqueológica a un sistema esclavista colonial parte de la hipótesis de que las grandes construcciones ganaderas de este tipo de asentamiento rural son el producto materializado y mejor constatable arqueológicamente del trabajo esclavo. Son estos restos materiales, entonces, los que nos permiten un primer acercamiento a las formas de vida de los esclavos.

\section{El asentamiento esclavista colonial de la Estancia de los Correa (Estancia del Oratorio)}

La introducción del trabajo esclavo en la zona está asociada al proceso colonizador, primero en el siglo XVIII a través del reparto de simples suertes de estancia ${ }^{2}$, y luego con la aparición de la gran estancia (latifundio) asociada a menudo a militares españoles. Este trabajo se focaliza en una de estas estancias del primer reparto colonial, la del Capitán de Caballería José Gerónimo de Sosa, conocida como Estancia del Oratorio o del Sauce. Se trata de un gigantesco latifundio, seguramente el más grande de Rocha y cuya denuncia ante Buenos Aires para legalizar el título de propiedad se realizó en 1786. Es un territorio de 43 leguas cuadradas (más de 100.000 has) cuyo frente está hacia el sur, hacia los cerros de Navarro, y que cierra hacia el norte en una zona de bañados hasta el pie de la Sierra de San Miguel. En su esquina noreste toca prácticamente la actual frontera entre Uruguay y Brasil. Por el este rodea la Laguna Negra e incorpora un tramo de la costa atlántica. El llamado Camino del Indio, de origen prehispánico y que permite sortear los bañados y los médanos del camino costero, discurre por esta estancia. Las denuncias de los títulos de propiedad de este latifundio realizada en 1801 por José Gerónimo de Sosa quedaron paralizadas en Buenos Aires hasta 1810 que conseguirá regularizar la propiedad (Sala, Rodríguez y De la Torre, 1968).

Cuando se produjo la invasión de la Banda Oriental por parte de Portugal, pasando a configurar la Provincia Cisplatina (1816-1828), las autoridades lusas animaron a familias poderosas de origen azoriano a comprar grandes estancias en la franja del actual Uruguay fronteriza con Brasil. La ocupación efectiva brasileña de esa franja y que los límites entre ambos países no quedasen definidos hasta después de la Guerra Grande (1839-1851), permitieron la circulación fluida de personas, ganados y bienes. Se trató de un territorio fronterizo móvil, permeable y tremendamente poroso (Dabezies, 2019; Dabezies, De Souza y Torena, 2017) que facilitó la implantación de un sistema esclavista dedicado a la explotación extensiva ganadera, protagonizado por latifundistas azorianos y por la presencia masiva de esclavos cuya manumisión estuvo asociada más a los procesos históricos brasileños que a la legislación oriental. Una de estas familias latifundistas fue la de Juan Faustino Correa, casado con Águeda Díaz de Oliveira, perteneciente a otra potente familia azoriana. En 1822 compraron la Estancia del Oratorio a la viuda de José Gerónimo de Sosa (Borucki et al., 2009; Chagas, Stalla y Borucki, 2012).

El matrimonio Correa-Díaz de Oliveira se instaló en el casco de estancia principal (El Oratorio), junto a sus hijos Serafín y Juan Faustino, mientras que otros cuatro de sus siete hijos fueron estableciendo nuevos cascos de estancia en el campo paterno. La nueva mensura practicada en la década de 1830 indicaba que la estancia estaba constituida por 21 leguas cuadradas dedicadas a la explotación agropecuaria, 5 leguas de "campo bajío" que solo permitía la alimentación de las reses y otras 17 de esteros y bañados. En total 43 leguas cuadradas (114.224 has, aproximadamente) haciendo de Juan Faustino Correa el mayor propietario territorial de Rocha.

Este latifundio colonial estaba conformado por un paisaje rural dominado por estos cascos de estancia en los que no había otro tipo de poblaciones hasta que Castillos fue fundada en 1866 y Santa Vitoria do Palmar en 1872. La capilla u oratorio fue

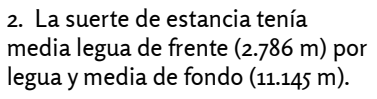
media legua de frente $(2.786 \mathrm{~m})$ por legua y media de fondo (11.145 m). 
construida hacia 1826. Además del casco y de algunas habitaciones próximas, las estructuras ganaderas completaban las construcciones, así como un cementerio con su correspondiente cerco en piedra. En ese núcleo rural vivían y trabajaban unos 24 esclavos (Borucki et al., 2009).

Los cascos de estancias de los hijos fueron establecidos aprovechando las rinconadas naturales. Al suroeste y sureste se ubicaban los cascos de Felicidad (junto a su esposo Joaquín Terra) con 10 esclavos, Ladislao con seis esclavos, y Francisco con 11 esclavos. En la zona noroeste estaba el límite natural de los bañados y se ubicaba la estancia de Justino, como puesto de control sobre campos altos y fácilmente accesibles, donde vivían seis esclavos. El límite norte eran campos intransitables, constituidos por el bañado de San Miguel y la cañada Grande. Los Correa controlaban el extenso campo y mediante la red de estancias secundarias en manos de los hijos evitaron contratar puesteros quedando toda la gestión del latifundio en la red familiar y los esclavos, dependientes de cada una de las cinco unidades de poblamiento (Borucki et al., 2009; Chagas et al., 2012) (Figura 1).

Esta estancia ejemplifica el paso de un sistema ganadero con esclavos de época colonial a un sistema esclavista estanciero-saladeril. Para 1831 allí vivían y trabajaban 61 afrodescendientes: 58 esclavos y tres párvulos libertos, lo que supone la mayor cantidad de esclavos (12\%) en la jurisdicción de Rocha, que contaba con un total de 480 esclavos y 50 libertos, y el $44 \%$ de los esclavos de Castillos. Más de la mitad de los 58 esclavos de las haciendas eran hombres, aunque esta ratio fue subiendo según avanzaba el siglo, pues en 1852 los hombres ya suponían el 72\% de los esclavos. Volviendo a los datos de 1831 el promedio de edad de los esclavos era de 19 años para los hombres y de 22 para las mujeres (Borucki et al., 2009; Chagas et al., 2012).

La expansión de la gran estancia ganadera azoriana en territorio uruguayo supuso la aplicación de un modelo donde la mano de obra fue casi exclusivamente esclava, orientando este trabajo coactivo a las diferentes labores agropecuarias, bajo la forma de esclavos campeiros (Osório, 2014). Este sector de Uruguay tuvo características socioeconómicas y productivas muy similares a Rio Grande do Sul, en claro contraste con el resto del Río de la Plata. Para sectores de Rio Grande do Sul se aprecia cómo a lo largo del siglo XIX los peones clasificados como indígenas cayeron notablemente respecto al siglo anterior (pasando del 62 al 18\%), frente a un importante ascenso de negros y pardos (Osório, 2014). El auge de este sistema esclavista de Uruguay ocurrió a mediados del siglo XIX sobre tres grandes ámbitos. Por un lado, la producción de ganado para cueros y tasajo para consumo regional. En segundo lugar, producción de ganado para los saladeros sobre todo de la ciudad de Pelotas (ubicada a unos 250 $\mathrm{km}$ ) donde se fundaron en 1780 los primeros establecimientos saladeriles en los que trabajaban casi exclusivamente esclavos entre 1814 y 1833 . Por último, la exportación del tasajo, alimento principal para esclavos de Cuba y de otras zonas de Brasil, como las explotaciones mineras de Minas Gerais (Funari y Menezes, 2016; Menezes, 2019; Palermo, 2005).

Este sistema no implicaba que todos los esclavos estuvieran dedicados exclusivamente a la pecuaria, pues en las estancias había variedad de tareas. Las fuentes citadas en Borucki et al. (2009) hablan de esclavos campeiros (ganaderos), roceiros (agricultores de las pequeñas chacras), curtidores y domadores. Los esclavos también podían trabajar en labores agrícolas. En cuanto a la infraestructura pecuaria, en sus manos estaba la explotación de canteras para levantar las mangueras y corrales, la construcción de establos, secaderos, graneros, y de los propios cascos de estancia. Un apartado específico lo constituye el trabajo femenino e infantil en el mantenimiento y reproducción de las tareas domésticas, por ejemplo, cocinado, tejiendo, lavando ropa, recogiendo leña y ordeñando las vacas, entre otras actividades (Borucki et al., 2009; Saint Hilaire, [1822] 1974). 


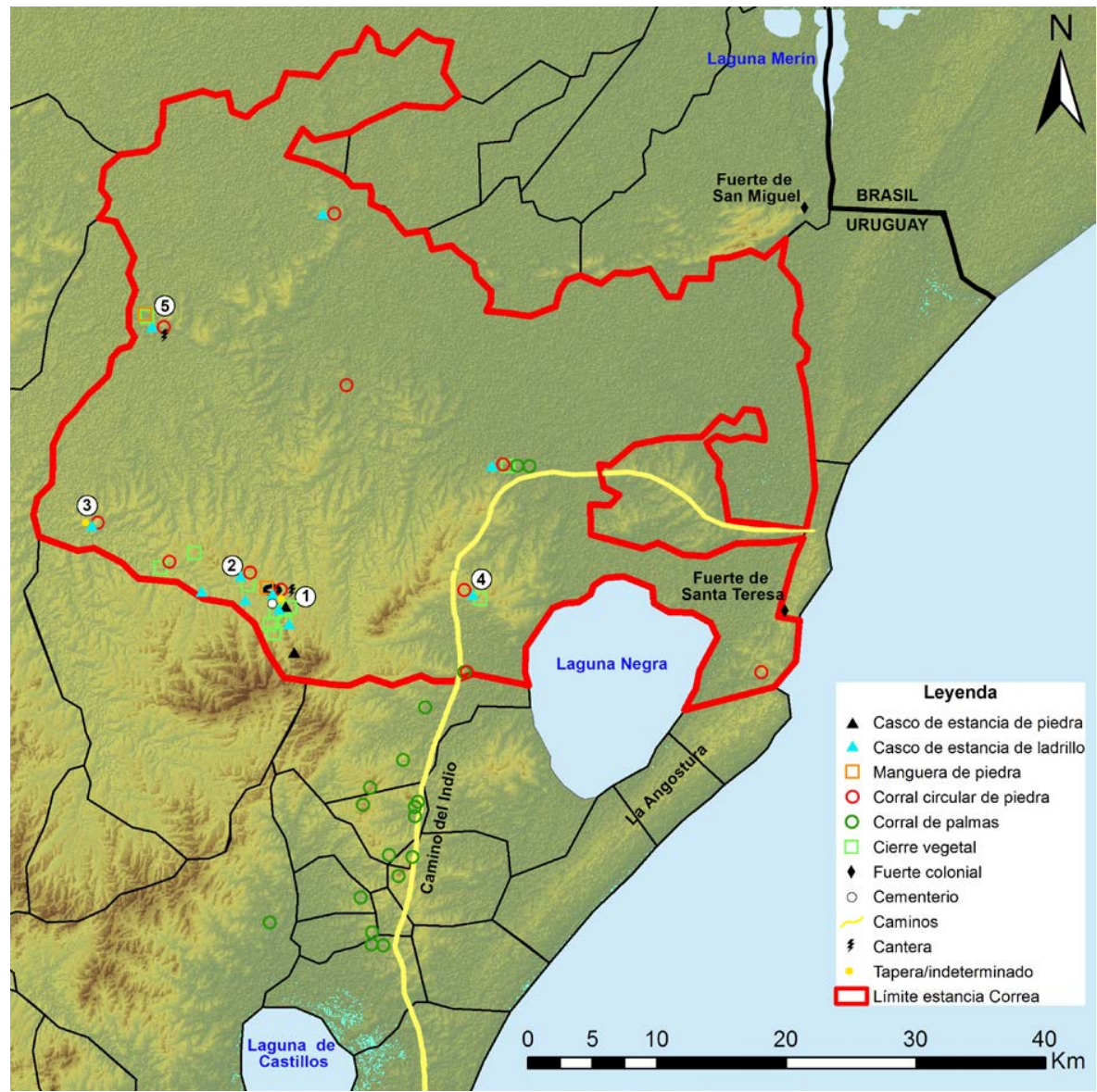

Figura 1. Mapa de la estancia el Oratorio de los Correa, con indicación de los principales cascos de estancia del patriarca y de los hijos. Referencias: 1) Juan Faustino Correa (Estancia del Oratorio); 2) Ladislao Correa; 3) Felicidad Correa y Joaquín Terra; 4) Francisco Correa; 5) Justino Correa.

El grupo familiar de los Correa fue uno de los mayores propietarios ganaderos de la región, con 14.600 reses declaradas (cerca del 54\% del ganado vacuno de la zona de Castillos y el $12 \%$ del contabilizado en el dpto. de Rocha Rocha). Por el número de esclavos y la extensión de su latifundio es probable que contaran con mucho más ganado del declarado (Borucki et al., 2009; Chagas et al., 2012).

El panorama esclavista comenzó a cambiar a mediados de siglo XIX, tras la Guerra Grande, cuando se fijó la frontera entre Uruguay y Brasil. Fue el momento en el que muchos esclavos pudieron conseguir la libertad tras su incorporación a los ejércitos, así como huir de sus antiguos amos. Hacia 1840, a causa de la guerra, los Correa tuvieron que emigrar a Río Grande do Sul y trasladar sus reses y esclavos. Luego de la guerra, la familia restableció sus haciendas en el territorio oriental y requirió la incorporación de esclavos, a pesar de la legislación abolicionista oriental aprobada en 1842 y 1846.

A mediados del siglo XIX la frontera seguía siendo un lugar de secuestro de negros, muchos antiguos soldados que se habían ganado la libertad participando en la Guerra Grande, y de tráfico ilegal de esclavos, con Castillos como uno de los epicentros de este fenómeno. Justino Correa denunció ante las autoridades orientales en 1852 la huida de ocho esclavos. A los dos días de haber hecho el reclamo los esclavos fueron devueltos por las autoridades orientales a cambio de que fueran contratados como peones (Borucki et al., 2009). 
Con la nueva legislación los "contratos de peonaje" se constituyeron en la herramienta para emplear trabajadores forzados, antiguos esclavos, y mantener formas parecidas a la esclavitud incluso hasta finales del siglo XIX. Es lo que algunos han denominado la "segunda esclavitud" (Tomich, 2004). Con este sistema en 1854 vivían 18 afrodescendientes en las haciendas de los Correa, triplicando el número de hombres al de mujeres. Los contratos de peonaje duraban 20 años de media, pudiendo llegar al doble; además podían heredarse por los hijos del patrón una vez muerto este e, incluso, ser aplicados a niños. El trabajo afrodescendiente continuó en forma casi exclusiva en la estancia bajo formas similares a la esclavitud, o peores (Borucki et al., 2009; Chagas et al., 2012).

La finalización del ciclo esclavista con la Ley Áurea de 1888 en Brasil puso un punto final en materia jurídica, aunque los contratos de peonaje sustituyeron la esclavitud por la servidumbre. El cambio trascendental en el afianzamiento de la "ganadería industrial" fue el alambrado de los campos. Entre 1872 y 1882 se cerraron de esta forma las estancias de prácticamente todo el país y se pasó a gestionar los ganados mediante potreros, expulsando mano de obra a los llamados "pueblos de ratas" es decir, depósitos de desocupados rurales en condiciones de extrema pobreza (Naohum, 2016). Estos pueblos de negros se formaron a partir 1860 a escasa distancia de la frontera, como una forma de protección contra eventuales cambios políticos (Palermo, 2005). En nuestra zona de estudio surgieron el Barrio Maturana, el Rincón de los Negros y la Portera Negra (Rocha, 2015) a donde se trasladaron los descendientes de los esclavos africanos que habían trabajado en la estancia de los Correa.

\section{Resultados arqueológicos}

En total se estudiaron 152 conjuntos de estructuras de la Estancia de los Correa y alrededores, de los cuales cinco se corresponden con los cascos de estancia de los Correa (patriarca y cuatro hijos) y 15 son conjuntos de estructuras pecuarias de la estancia realizadas en piedra (tres son mangueras de piedra y 12 conjuntos de corrales circulares de piedra, de los cuales cinco sólo pudieron ser estudiados por fotografía aérea). En uno de estos lugares conocido como el cementerio del Oratorio se practicó una excavación arqueológica.

El análisis espacial de la estancia permitió identificar con claridad su perímetro y observar cómo sus límites norte y noroeste se vinculan con conjuntos de estructuras indígenas (cerritos de indios) en la zona de los bañados de India Muerta y en la sierra de los Ajos (Bracco, Cabrera y López Mazz, 2000). El Camino del Indio, eje de comunicación principal que atraviesa la estancia de sur a norte, está asociado también a conjuntos de estructuras indígenas ubicadas en las colinas por donde discurre dicho camino, próximas a los bañados de las Maravillas y a la Laguna Negra (López Mazz, 2001). No parece casual que en 1768 José Gerónimo de Sosa, el primer propietario de la estancia, usara el límite natural de los bañados y los conjuntos de estructuras monumentales correspondientes a montículos indígenas (Gianotti, 2015) para marcar los límites de la finca que reclamó antes las autoridades de Buenos Aires. Esta situación de frontera indígena es coherente con la información histórica que señala el progresivo desplazamiento de los grupos indígenas güenoa-minuanes, entre ellos el gran cacique Miguel Caraí Zapata, que habitaba previamente al suroeste de la Laguna Merín y que luego se asienta en unos bañados próximos al río Piraí, en el actual territorio brasileño (López Mazz y Bracco, 2010). Por tanto, esta primera ocupación colonial del territorio no se produjo sobre un espacio virgen, sino que realmente supuso la apropiación y despojo de un territorio articulado por un paisaje indígena estructurado (cerritos de indios, tolderías, vías de comunicación) y que estaba en uso en esas décadas de finales del siglo XVIII (Saldanha, 1998). 
En este sentido es interesante reseñar la disposición y estructura de los 16 corrales circulares de palma Butia odorata documentados en esta zona, de los cuales tres están dentro de la estancia. Estos corrales se crearon mediante el trasplante de palmeras jóvenes, pues todas ellas tienen un estrechamiento a una altura que varía entre 1,5 y $2 \mathrm{~m}$, generado por el estrés del trasplante de la palma cuando tenía esa altura. Se trasplantaron dejando espacios entre ellas de unos $30 \mathrm{~cm}$ y forman cierres que tienen de media 0,20 ha. Estos corrales fueron usados para el encierro y manejo de ganado. El naturalista francés Augustin Saint-Hilaire ([1822] 1974) pasó por estas tierras de Castillos en torno a 1820 y describió dichos corrales especificando que estaban formados por palmeras adultas. Además, uno de los corrales de mayores dimensiones fue acondicionado posteriormente con piedras adosadas a las palmas, generando una clara cronología relativa (Figura 2). Como veremos, los corrales circulares de piedra los podemos asociar con las estancias azorianas del siglo XIX. Además, la distribución de los corrales circulares de palma es lineal, jalonando el mencionado Camino del Indio y siguiendo por tanto una lógica espacial que no se ajusta a los límites de las estancias coloniales. Todo ello lleva a pensar que estamos ante los testimonios vivos de la primera ganadería del Uruguay, aquella practicada por los indígenas güenoa-minuanos que gestionaron las "vaquería del mar" y que a lo largo del siglo XVIII vendían regularmente ganados a los portugueses de Rio Grande do Sul. Ello explicaría por qué el otro gran conjunto de este tipo de corrales se encuentra en la cercana Santa Vitoria do Palmar, indicando un eje ganadero de sur a norte.

El relevamiento de campo también reconoció a nivel macro regional estructuras en piedra correspondientes a antiguas guardias coloniales (torre de Antel de Castillos, Cerro de los Rocha y Guardia del Monte/laguna de Castillos). Estas guardias documentadas históricamente datan de la primera mitad del siglo XVIII y son previas al reparto colonial de estancias. Al principio articulaban la frontera indígena, luego las fronteras imperiales, pero desde fines del siglo XVIII marcaron y aseguraron el tránsito entre los dominios español y portugués. El paisaje colonial inicial se completa con algunas mangueras de piedra relevadas en el cerro de los Rocha (que la tradición oral vincula a los indios guaraníes) y la Fortaleza de Santa Teresa, objeto de varias disputas hasta el siglo XIX.

Volviendo al interior de la estancia de los Correa hemos podido identificar una serie de estructuras que seguramente sean el testimonio de la primera ocupación de ésta por parte de José Gerónimo de Sosa en los años 70 del siglo XVIII. Se trata de tres cascos de estancia hoy en ruinas, realizados íntegramente en piedra, organizados en módulos rectangulares que se estructuran en L y que se concentran entre el Oratorio y el límite sur de la estancia. Seguramente la fase más antigua del Oratorio se corresponda también con esta época. Todo ello indica que el principal núcleo habitado en época colonial fue la zona del Oratorio, motivo por el cual cuando el latifundio fue comprado por los Correa ubicaron allí la sede del patriarca, reocupando estructuras que ya estaban en uso. Es por este motivo que la morfología arquitectónica del casco de estancia del Oratorio difiere tanto con respecto a las de los hijos, pues supuso la reutilización de una estructura previa. En líneas generales se trata de cascos de estancia que recuerdan bastante al cercano de la Tuna, bien datado en época colonial (Martínez Rovira, 1982). La gestión ganadera que se vincula a esta fase del siglo XVIII está representada por dos mangueras de piedra (muros lineales), que encierran gigantescos espacios. Una está ubicada en el Oratorio y tiene una superficie de $487.000 \mathrm{~m}^{2}$ (Figura 3), y otra en lo que posteriormente será el casco de estancia de Justino Correa, con una superficie de $1.523 .000 \mathrm{~m}^{2}$.

Los corrales y las mangueras son construcciones realizadas en sillares y sillarejos de piedra, colocados a piedra seca, con muros muy bien trabados, y anchuras medias de 1 $\mathrm{m}$. En la mayor parte de sus tramos están muy desmontadas, seguramente por haberse 

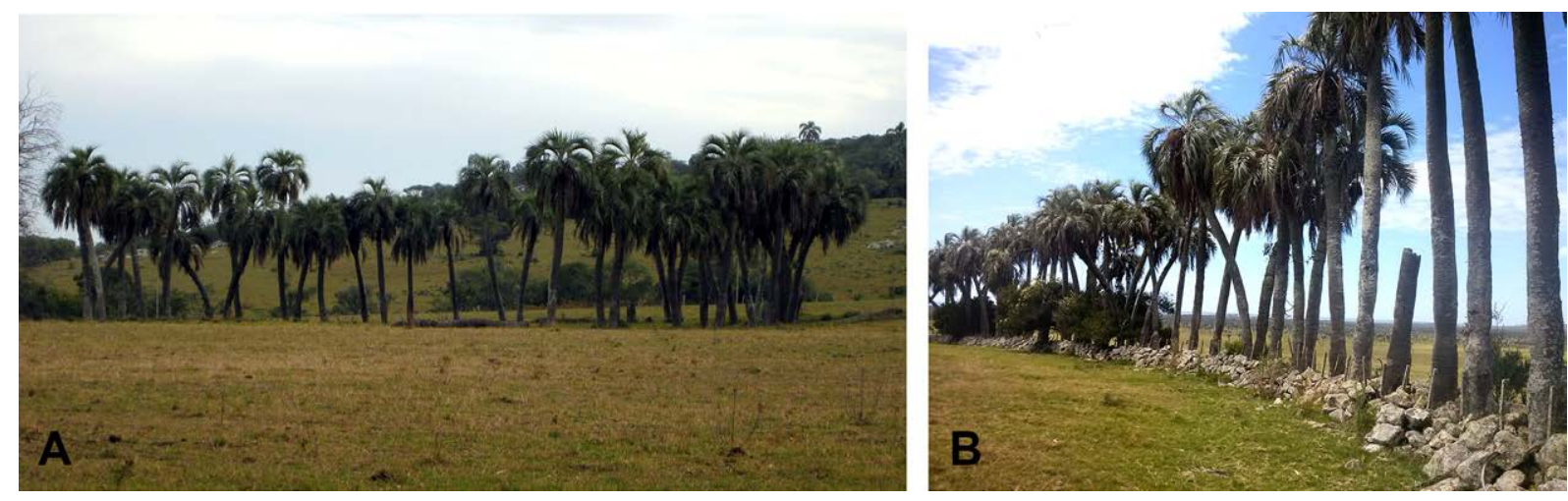

Figura 2. Corrales. A) corral circular de palmeras Butia odorata; B: superposición de corral circular de piedras a un corral circular de palmeras. Ambos se ubican en el Camino del Indio.
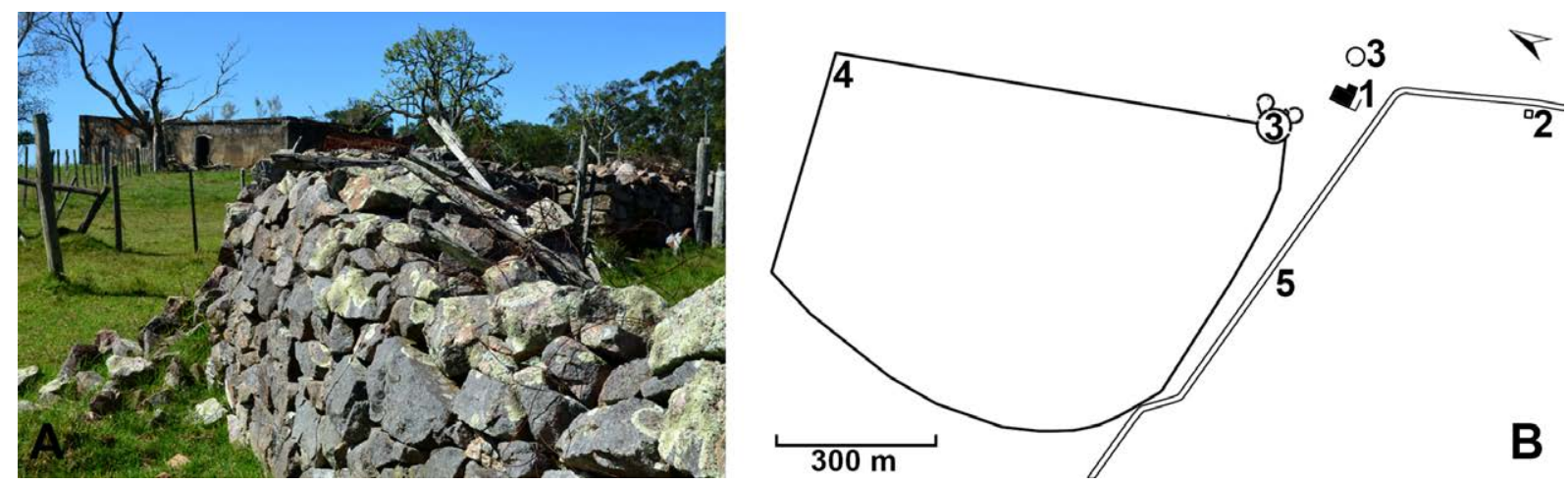

Figura 3. Estancia del Oratorio. A) vista del casco de la estancia desde los corrales circulares de piedras; B) esquema de las principales estructuras de este conjunto: 1: Casco de estancia, 2: Cementerio, 3: Corrales circulares de piedra, 4: Gran corral de piedra/manguera, 5: Camino actual.

utilizado sus piedras para nuevas construcciones (por ejemplo, los corrales circulares). En la manguera vinculada al último lugar mencionado se observan subdivisiones internas realizadas con árboles nativos y bastante longevos, lo que indica que pudieron haber sido plantados en la época. También es la zona del Oratorio la que contiene más cierres vegetales de este tipo, especialmente hacia el sur del mismo, vinculados a los cascos de estancia de piedra mencionados. Por tanto, la gestión ganadera de este primer momento pasó por la construcción de grandes corrales de piedra donde atesorar el abundante ganado de aquel territorio que entonces se reclamaba. También es interesante señalar que la manguera del Oratorio es infrayacente a los posteriores corrales circulares, que fueron construidos seguramente con el desmontaje de aquella (Figura 4).

Pasando a la fase posterior, caracterizada por la familia Correa y por la imposición del sistema esclavista estanciero-saladeril, podemos ver cómo la mayor concentración de estructuras sigue estando en el lugar del Oratorio. Parte del casco de estancia principal seguramente vendría de la época de José Gerónimo de Sosa y fuese remodelado por los Correa. No obstante, las continuas transformaciones del sitio, y en concreto la remodelación general que sufrió en los años 60 del siglo $\mathrm{XX}$, hacen que sea muy complejo el estudio arquitectónico del lugar, aunque cabría pensar que la fachada principal es una remodelación de la fase de los Correa, pues se orienta al norte en consonancia con la tradición portuguesa. Sin embargo, en la parte trasera, en donde la tradición sitúa la capilla, no quedan restos que puedan ser vinculados con dicha construcción. También es difícil poder interpretar las numerosas taperas que rodean 


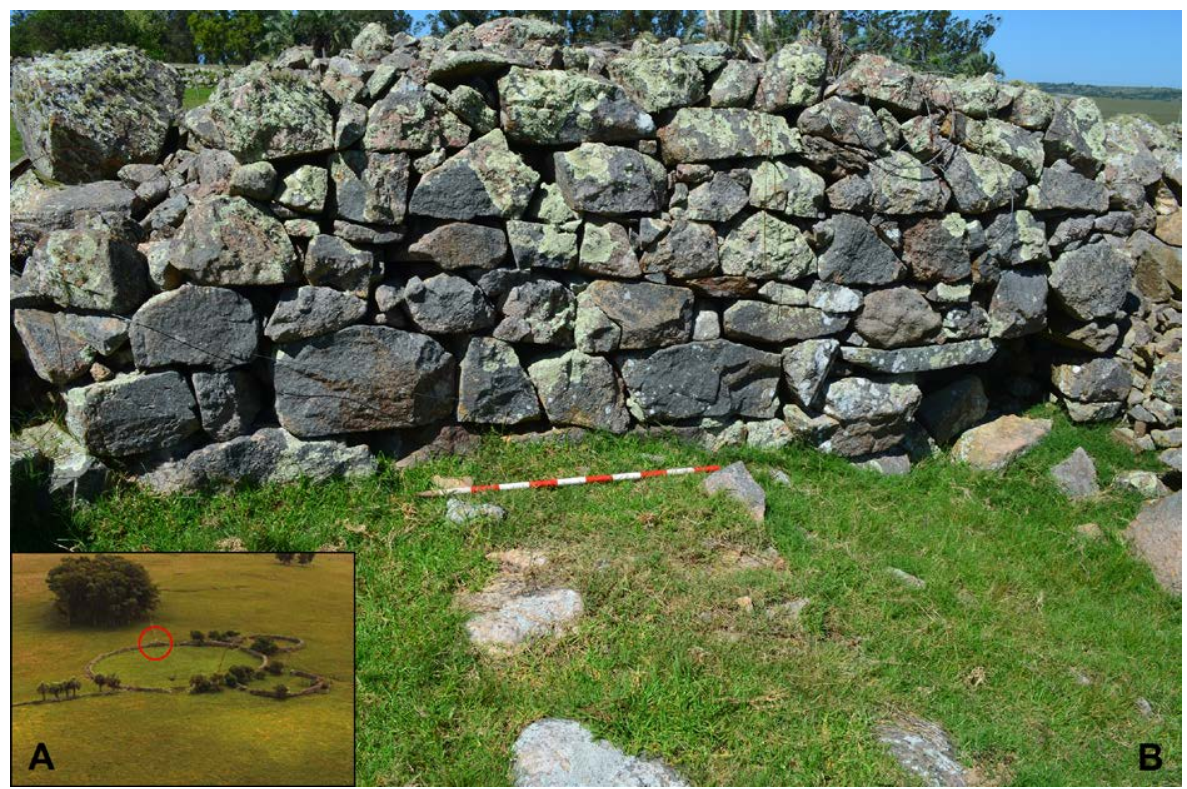

Figura 4. Superposición estratigráfica de las estructuras murarias de los corrales de piedra en el Oratorio de los Correa. A) imagen aérea donde se indica el sector superpuesto; $B$ ) detalle de la superposición estratigráfica de un corral circular de piedras sobre una antigua manguera de piedras.

al edificio principal. Los corrales circulares de piedra, construidos seguramente en el período de aumento de la mano de obra esclava, se han mantenido más o menos en buen estado gracias al continuado uso para trabajos ganaderos. El Oratorio cuenta con hasta cuatro corrales circulares de piedra, mientras que las estancias secundarias solo cuentan con un corral circular cada una. Su corral principal tiene unos $60 \mathrm{~m}$ de diámetro, al que se le añadieron tiempo después dos más de casi $30 \mathrm{~m}$ de diámetro. Separado de este conjunto se encuentra el cuarto corral, también de casi $30 \mathrm{~m}$ de diámetro (Figura 5). Estas estructuras de piedra están formadas por paramentos con grandes sillares en la base y alturas de hasta dos metros, mientras que las paredes tanto internas como externas se encuentran ligeramente ataludadas, dejando bases más anchas que las cumbreras de los muros. Tienen entre una y tres puertas y en varios casos muros asociados a las puertas para ayudar a introducir el ganado.

En el Oratorio hay dos medidas de corrales circulares, el mayor de $60 \mathrm{~m}$ de diámetro y los otros tres de en torno a $30 \mathrm{~m}$. Las estancias de los hijos de Juan Faustino Correa (Justino Correa, Francisco Correa y Felicidad Correa) aunque tienen un sólo corral, estos alcanzan $90 \mathrm{~m}$ de diámetro. La anexión de corrales circulares en el Oratorio y el hecho de que en las estancias de los hijos los corrales sean de mayor tamaño, pueden estar indica un aumento del número de cabezas de ganado en el latifundio según fue avanzando el siglo XIX. Esta tipología de corrales circulares de piedra se reparte principalmente por el sector uruguayo en donde encontramos estancias azorianas (Martins Farias, 2013), por lo que cabe pensar que se trata de un tipo de estructura representativa de este sistema ganadero esclavista, que fueron construidos con mano de obra esclava y que deben datarse principalmente en el siglo XIX.

La tradición indica que la estructura cuadrangular que se encuentra al sur del Oratorio era el cementerio principal de la familia Correa. Hasta no hace mucho tiempo los habitantes del Barrio Maturana seguían llevando flores y velas a este lugar. La construcción parece vinculada a la familia Corea pues fue realizada con unas medidas de "seis varas en quadro" (VVAA, 1966) es decir seis toesas, medida de longitud portuguesa que equivale a $1,98 \mathrm{~m}$ y que da como resultado los casi 12 


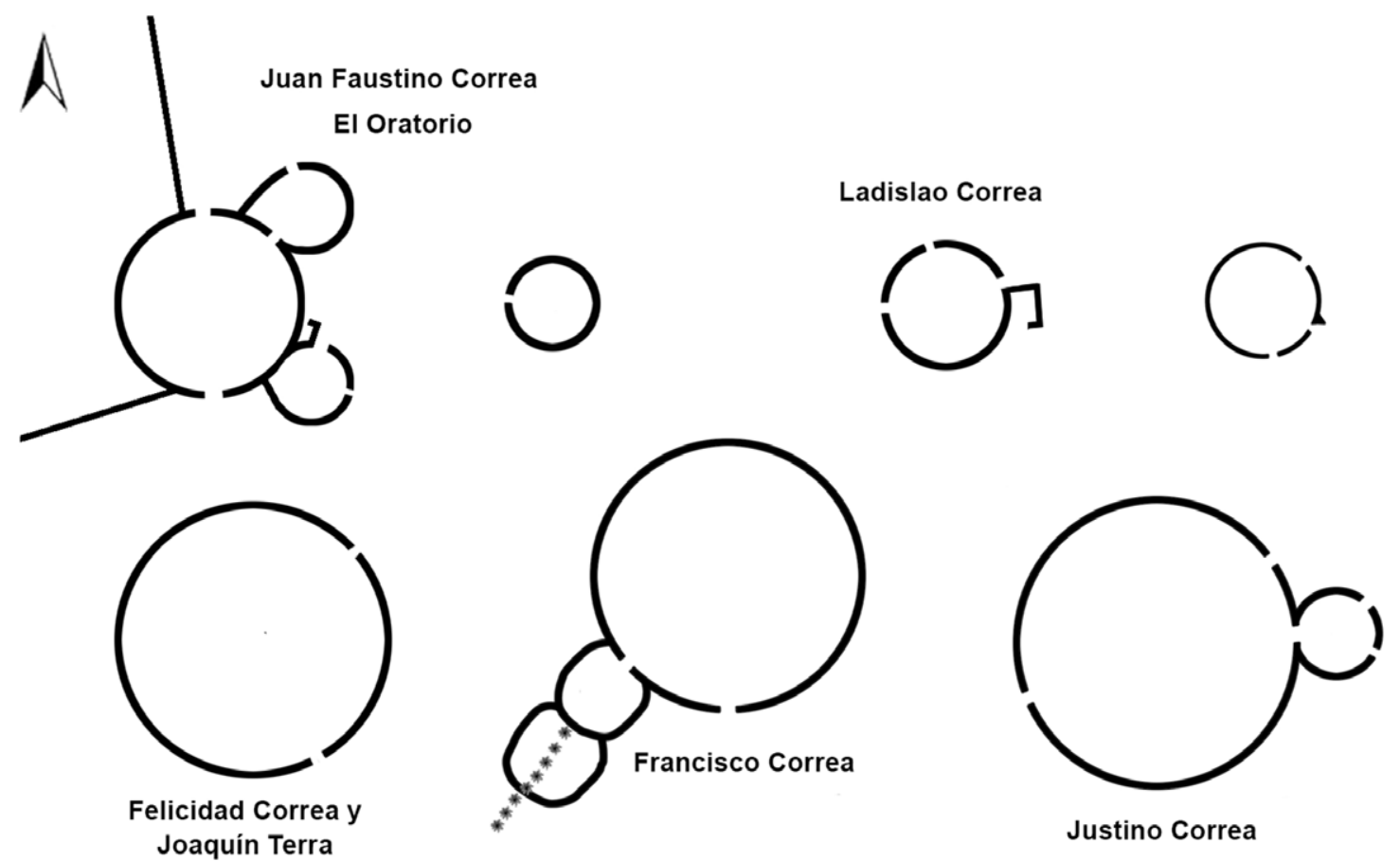

Figura 5. Corrales circulares de la estancia del Oratorio de los Correa. Se representan aquellos asociados directamente a los cinco cascos de estancia principales.

$m$ de lado de esta estructura. En ese lugar, se realizó una trinchera de lado a lado para poder constatar la funcionalidad del interior de esta construcción muraria. Cuando la excavación llegó a un nivel de tumbas se amplió puntualmente la trinchera para analizar la organización y los patrones constructivos de las mismas, pero sin realizar ninguna exhumación. Se pudieron observar hasta 11 enterramientos, con una disposición general noreste-sudoeste, siendo la mayoría de ellos en fosa simple y cubierta con acumulación de piedras. Solo se pudo localizar un enterramiento más moderno, con cajón de madera y remaches metálicos, que cortaba tumbas más antiguas (Figura 6). En contraste con este cementerio, la tradición local sitúa el cementerio de los esclavos al norte del Oratorio (VVAA, 1966). En nuestras prospecciones pudimos localizar en ese sector numerosas canteras donde se extraía y canteaba la piedra. Una de ellas llama la atención por haber sido rellenada. Trabajos futuros buscarán conocer el porqué de ese relleno.

Respecto a los cascos de estancia de los hijos de Juan Faustino Correa, en líneas generales siguen un patrón común. Estos antiguos cascos de estancias son los asentamientos humanos de mayor jerarquía geográfica y edilicia y se ubican en estratégicos lugares del relieve, desde donde se pueden ver los límites de la unidad productiva, los fondos de los valles y los caminos. Cada uno de ellos está asociado a un corral circular, entre otras estructuras. Están construidos en ladrillo, con paredes enlucidas, que dejan un gran patio central en donde se sitúa un pozo, siguiendo la tendencia del resto de la campaña uruguaya para el siglo XIX, que es de clara inspiración ibérica (Gómez, 2012). Pese a las remodelaciones sufridas, en algunos casos tuvieron una segunda planta a modo de torre. En uno de los brocales aún se conservan las iniciales del patriarca (JFC) realizados en forja. En los laterales del patio se sitúan las habitaciones principales, mientras que en el lado opuesto se ubica un gran galpón, que puede estar construido en piedra, y que seguramente se usase 

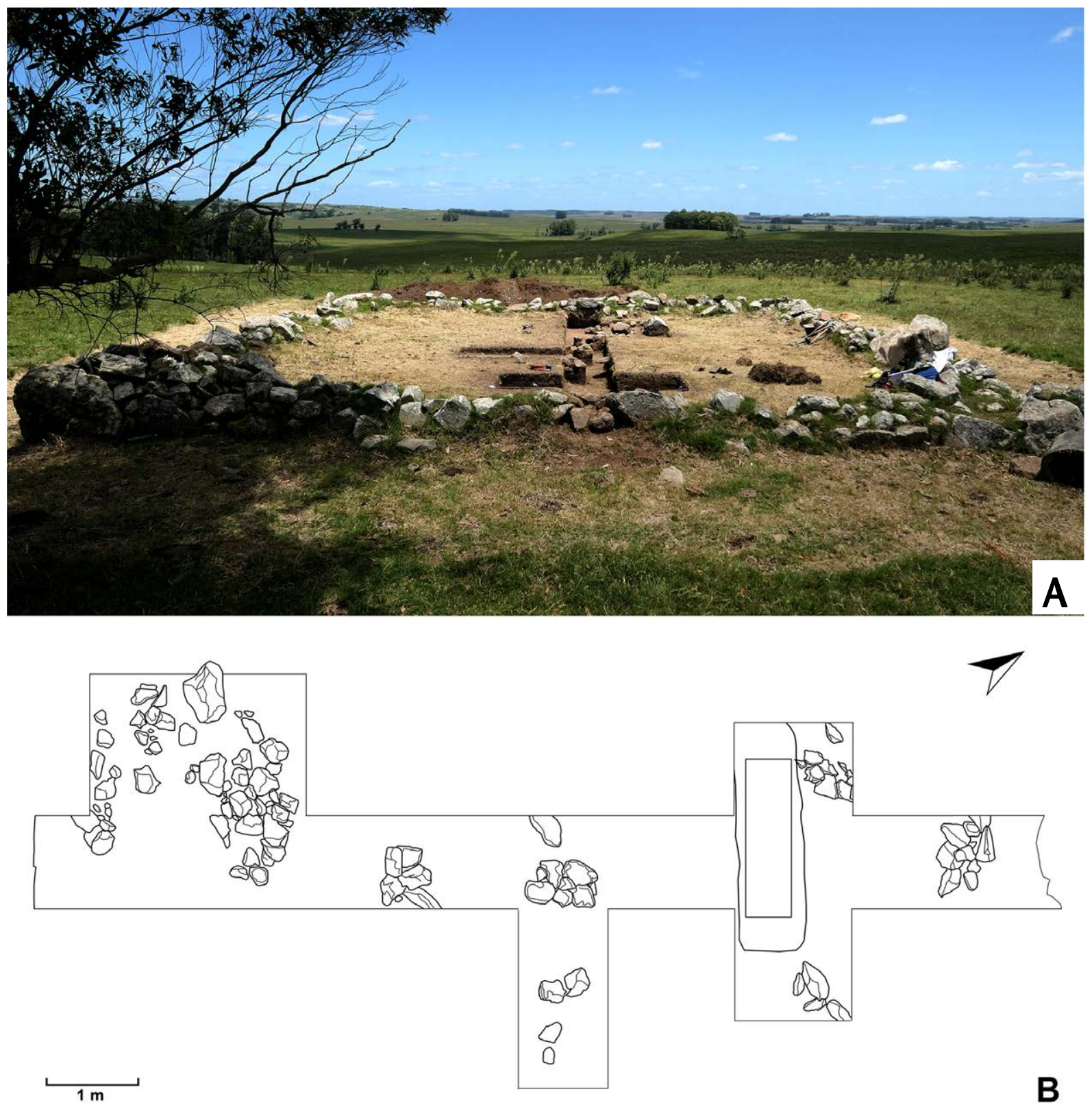

Figura 6. Cementerio del Oratorio. A) vista general desde el este con el sector de excavación abierto; B) planimetría del nivel de cubiertas -encachados de piedras- de los enterramientos.

como caballerizas y almacén (Figura 7 y Figura 8). En la estancia de Felicidad Correa y su marido Joaquín Terra se conserva la fecha 1838 en la puerta del galpón. En el caso de la de Francisco Correa la fecha que figura en la puerta principal es 1860 (modificando la fecha original que figuraba, que era 1850). Las habitaciones laterales del patio o los galpones traseros pudieron haberse usado para alojar esclavos, así como en algunas de las taperas documentadas. En esta línea es interesante reseñar que a unos $35 \mathrm{~m}$ fuera de la estancia de Francisco Correa existen unas estructuras que por la tipología muraria parecen contemporáneas de la estancia (Figura 9). Estas estructuras replican hasta cuatro veces un módulo compuesto por una habitación de pequeñas dimensiones con puerta de entrada y ventana. Investigaciones futuras deberán explorar si se trata de antiguos alojamientos para esclavos. 


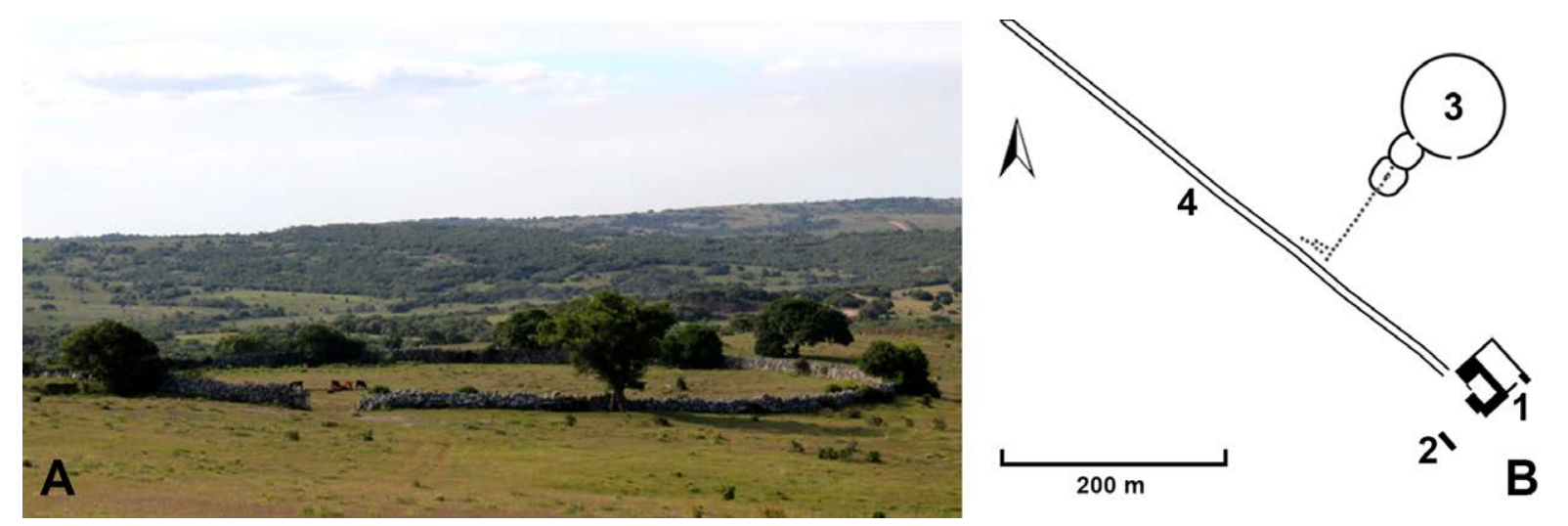

Figura 7. Estancia de Francisco Correa. A) vista general del corral circular de piedras visto desde el casco de estancia; B) esquema de las principales estructuras de este conjunto: 1: Casco de estancia con patio central y corral cuadrangular asociado, 2: Posible alojamiento de esclavos, 3: Corral circular de piedras, 4. Camino actual.
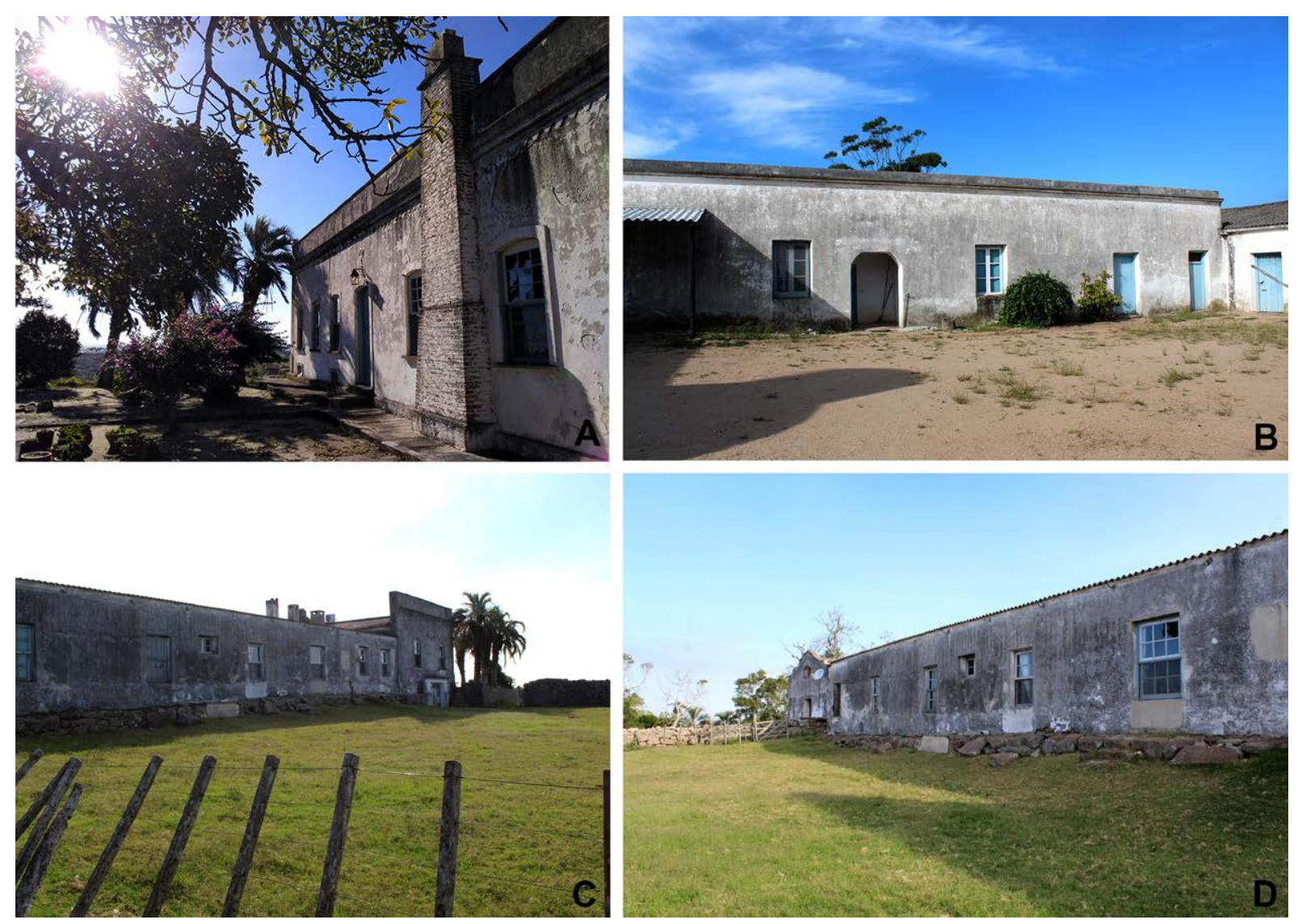

Figura 8. Vistas del casco de estancia de Francisco Correa. A) fachada principal (estado actual tras desmontaje de la torre a comienzos del s. $X X)$; B) patio principal con piezas para peones, capataz y comedor, y arranque del galpón principal; C) fachada lateral con parte noble a la derecha y habitaciones para peones, capataz y comedor a la izquierda; D) vista similar a la anterior, en donde se aprecia el galpón que cierra el conjunto arquitectónico por el sureste.

En el caso de la estancia de Felicidad Correa, a la altura de la puerta del galpón reseñado, se sitúan las "antiguas cocinas", que también deberán ser objeto de futuros trabajos, pues pueden estar indicando lugares de trabajo esclavo femenino (Figura 9).

Por último, el asentamiento de negros llamado la Portera Negra se sitúa fuera de la estancia, junto al Camino del Indio. Nacido a fines del siglo XIX con los antiguos 

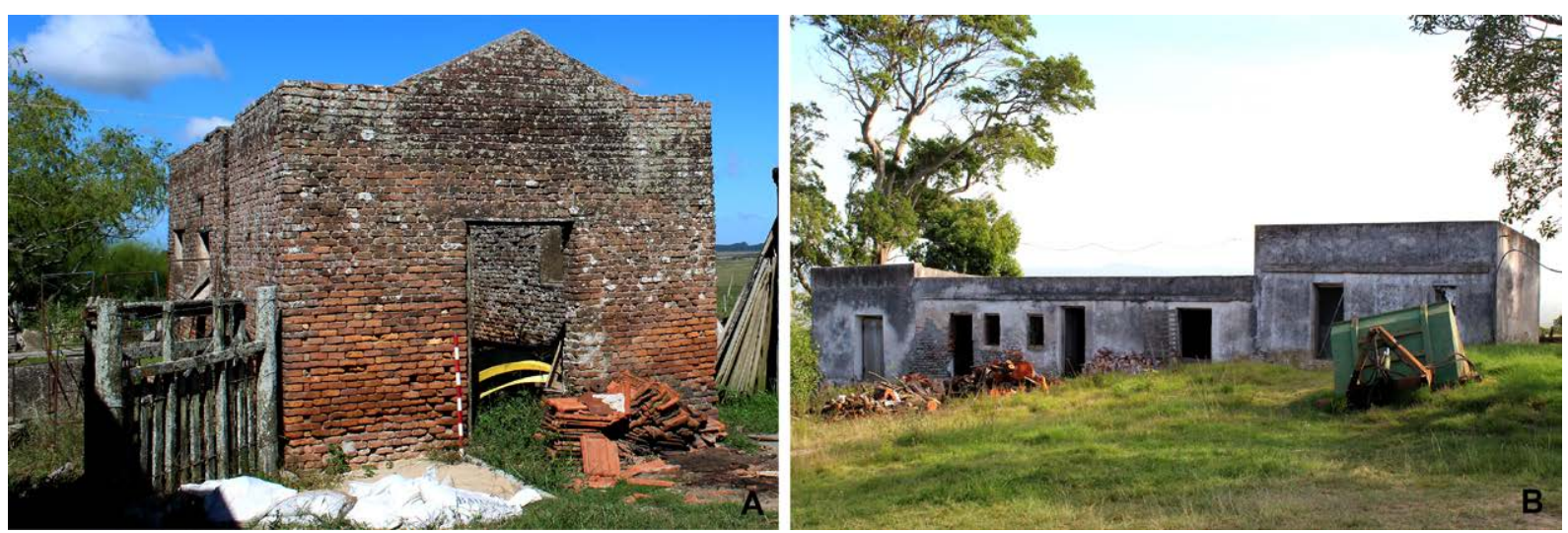

Figura 9. A) "antiguas cocinas" de la estancia de Felicidad Correa y Joaquín Terra; B) estructuras de habitación próximas al casco en la estancia de Francisco Correa.

esclavos de las estancias, estuvo en uso hasta los años 60 del pasado siglo, cuando muchos de sus habitantes se trasladaron a Castillos y a Montevideo. En ese lugar se pudieron relevar, asociadas a un antiguo almacén sobre la ruta 13, una serie de taperas y micro relieves que corresponden a las unidades habitacionales de las familias que allí residieron. Los investigadores locales Jesús Perdomo y Raúl Rocha realizaron con los antiguos habitantes una reconstrucción de las estructuras del asentamiento. En el mapa que confeccionaron muestran hasta 16 unidades domésticas, con los nombres de sus habitantes (Figura 10), una pista donde se hacían carreras de caballos, una zona central de encuentro para las fiestas y una cañada en donde las mujeres hacían la colada para las estancias cercanas. En al menos tres de las casas se ven apellidos Correa, lo que indica que son descendientes de los esclavos de la estancia del Oratorio.

\section{Discusión y conclusiones}

Este trabajo produjo información que permite profundizar al estudio de los procesos históricos, culturales y económicos, asociados a las comunidades de afrodescendientes de la frontera este de Uruguay. La investigación permitió constatar un complejo escenario interétnico en el que estaba inmersa la esclavitud y conocer mejor el desarrollo de la ganadería local. La reconstrucción arqueológica de los sistemas pecuarios le da profundidad histórica a una de las actividades centrales en el Uruguay de hoy, mediante la identificación de varios momentos. La primera fase está representada por los corrales circulares formados por palmeras trasplantadas que pueden estar vinculados a las vaquerías del mar, y por tanto a los saberes y la mano de obra de las sociedades indígenas locales, que son las primeras comunidades que desarrollaron la ganadería. En un marco de inestabilidad geopolítica y de lucha de las potencias coloniales por fijar la frontera y ocupar el territorio parece que existió una fluida dinámica ganadera protagonizada por indígenas.

Posteriormente, el desarrollo de la ganadería extensiva en la zona está marcada por el reparto colonial de estancias y la ocupación efectiva de la frontera. La participación de las sociedades indígenas en el desarrollo de la actividad ganadera criolla está documentada entre otras cosas en la obtención de marcas de ganado propias a fines del siglo XVIII (Martínez Rovira, 1982). Existen mangueras de piedra y cascos de estancia en piedra en El Oratorio posiblemente de esta fase, vinculados a José de Sosa, el primer propietario.

La tercera fase del desarrollo de la pecuaria está marcada por la implantación de las estancias azorianas y del sistema esclavista estanciero-saladeril de fines del siglo XVIII 


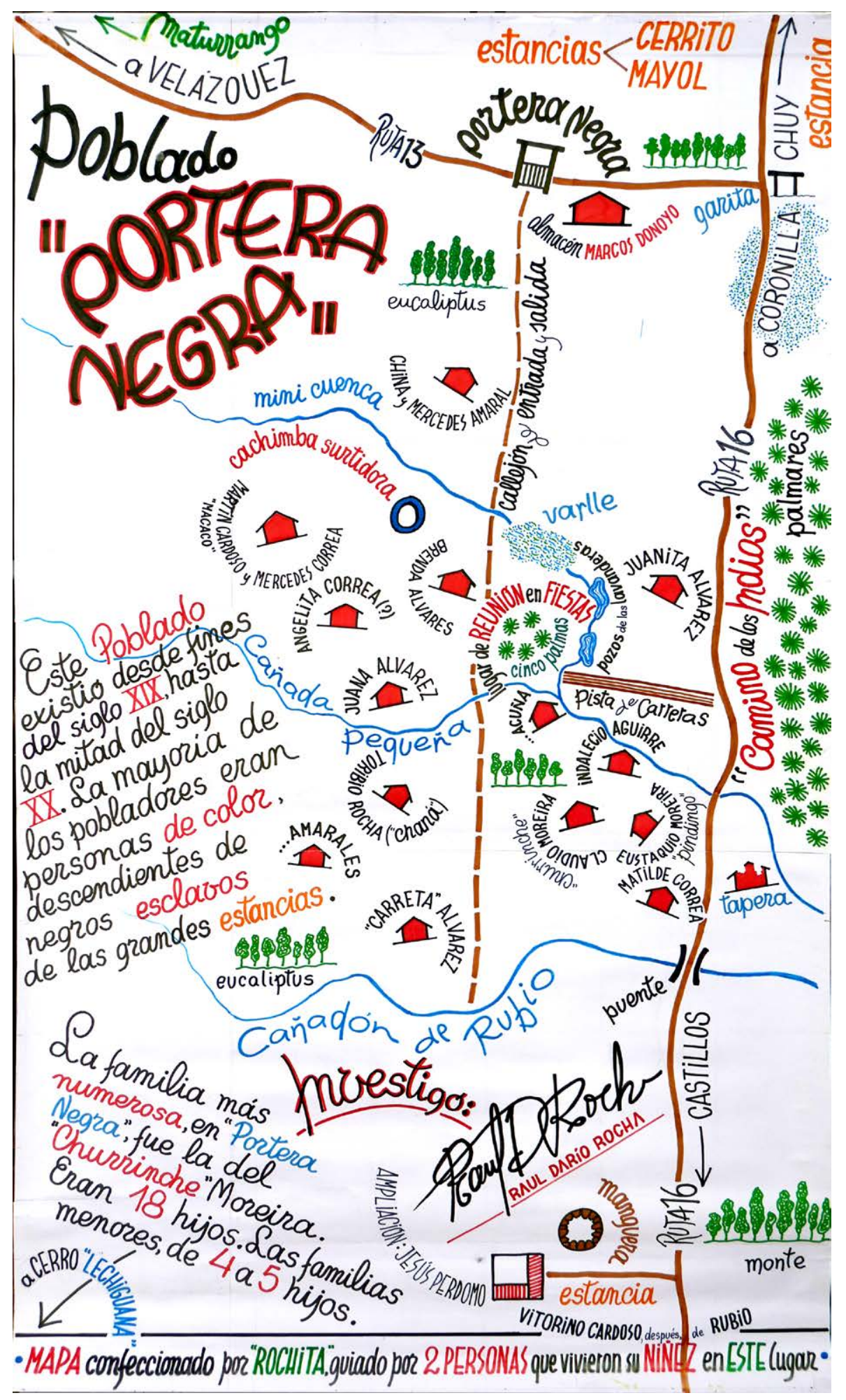

Figura 10. Mapa del "poblado de ratas" la Portera Negra, realizado por Raúl Rocha con información provista por algunos de los últimos habitantes del lugar (años 60 del s. XX).

y comienzos del siglo XIX. En el este de Uruguay el desarrollo de la actividad ganadera y su progresiva tecnificación estuvo asociado casi en exclusividad a la mano de obra de comunidades de esclavos africanos, particularmente amortizada en la construcción de 
infraestructura ganadera. Poco antes del comienzo de la República Oriental la compra de la estancia de El Oratorio por los Correa ilustra un período de penetración de grandes estancieros brasileros como una forma efectiva de controlar el territorio que se reclamaba a nivel político. A la llegada de los Correa (inicios del siglo XIX) las estructuras en piedra aumentan en número y se aplicaron nuevos diseños (corral circular de piedra).

La investigación de las estructuras de la Estancia del Oratorio de los Correa ha permitido documentar en este gran latifundio asentamientos de primera y segunda jerarquía, en los que se repiten patrones morfológicos y tecnológicos en la confección de la estructuras domésticas y ganaderas. Creemos que el relevamiento da cuenta de algunas de las materializaciones del trabajo esclavo de un espectro mucho más amplio de actividades no directamente observables. En primer lugar y sobre todo sobresalen las estructuras ganaderas en piedra y los cascos de estancia en ladrillo.

En las estancias relevadas existe una relación directamente proporcional entre el número de esclavos registrados en la documentación histórica y el volumen del trabajo amortizado en las construcciones, tanto en piedra como en ladrillo que pudimos relevar. Esta relación no aleatoria entre esclavos y muros en piedra está en línea con la relación (también directamente proporcional) previamente observada por los historiadores, entre tamaño de la propiedad, cantidad de ganado y número de esclavos (Osorio, 2004). En relación al sistema constructivo de las estructuras en piedra, hemos podido identificar para cada casco de estancia y conjunto de estructuras ganaderas, las canteras donde se extraían y canteaban los sillares y sillarejos (Figura 1).

Este modo de producción esclavista se centró en el manejo de ganado principalmente bovino, y en la acumulación de trabajo en actividades especialmente duras como la construcción en piedra. Esta tecnología modernizó el sistema extractivista ganadero, facilitando la acumulación de ganado, la gestión de calidad del mismo, el traslado de tropas a los grandes mercados extra regionales y la industrialización. Estas actividades de procesamiento intensivo y especializado de subproductos ganaderos (extracción de cueros, carne salada, grasa, cebo, etc.) demandaron, como está documentado, gran cantidad de fuerza de trabajo esclava.

La instalación del sistema ganadero esclavista en la transición entre la colonia y la República se articuló con un paisaje precolonial indígena con importante profundidad temporal, del cual aprovechó la estrategia y las formas de ocupar las tierras inundables. El sistema esclavista recuperó de las experiencias históricas y prehispánicas relativas a la gestión de ese paisaje, en particular el acceso a los caminos, así como el control visual de los límites geográficos y de los campos de invernada, que era donde se reunía el ganado a pastar. Y esa ha sido la clave sobre la cual se ha construido y consolidado la territorialidad del sistema agropecuario actual.

Para algunos autores la producción pecuaria y la esclavitud serían actividades incompatibles (Prado, 1945). No obstante, habría que analizar en profundidad el rol de los esclavos "curraleiros" y "campeiros", indisolublemente ligados a la propiedad extensiva de la tierra. La clave de este sistema esclavista rural sería, según Helen Osório (2004), el matrimonio de esclavos, la unidad básica de mano de obra para estos establecimientos ganaderos. Este sistema esclavista tiene peculiaridades, como son la relativa libertad de movimientos de los esclavos asociada a los necesarios desplazamientos con tropas al interior de un extenso territorio, y la posibilidad de tener familia. La organización familiar del trabajo esclavo y la posibilidad de cultivar, serían la estrategia efectiva para la coacción al trabajo según investigaciones sobre fines del siglo XIX (Faría, 1998). Esto contrasta fuertemente con otros sistemas esclavistas americanos como las plantaciones, donde la mano de obra esclava estaba fija y circunscripta a un espacio limitado y controlado (Gomes Coelho, 2017). 
La especificidad histórica, cultural y geográfica de la esclavitud africana en esta zona de América comienza a configurar un mapa del problema, a la vez que alimenta la memoria histórica de este colectivo de descendientes crónicamente postergado. Al hacer visible y poder cuantificar el trabajo esclavo, se puede justipreciar la contribución de este grupo humano a la historia de esta región del Uruguay, y al origen de la ganadería industrial. El relevamiento arqueológico facilitó localizar, identificar y hacer visibles las construcciones ganaderas en piedra que la tradición oral y la historia local atribuían a los esclavos. Si bien acá se presentan los primeros resultados de la investigación, algunos indicios son promisorios para orientar futuras investigaciones más específicas, en busca de la localización de los espacios funerarios y domésticos.

La esclavitud es un tema histórico y social no claramente resuelto en el este de Uruguay, donde la vida de los descendientes de esclavos está aún marcada por la pobreza y la discriminación. El indio resistió e hizo fracasar los proyectos esclavistas que al principio de la conquista habían tratado de cooptarlo como "esclavo rojo". En ese contexto el trabajo esclavo africano llenó el vacío dejado por la mano de obra indígena, que se integrará de manera autónoma e independiente al proyecto ganadero colonial. La historia de la ganadería en Uruguay está marcada por experiencias interétnicas que recogen y son tributarias de diversas formas de gestión de la naturaleza. Pero entre todas las instancias será decisivo el impacto del trabajo esclavo como un factor central en la consolidación de este peculiar modo de producción ganadero.

A modo de epílogo, podemos decir que el despoblado llamado la Portera Negra constituye por su parte un documento singular de la vida doméstica y comunitaria durante los primeros 100 años post esclavitud. En este caso los relevamientos de campo cuentan con los invalorables testimonios orales recogidos por los historiadores locales. Esto fortalece los estudios arqueológicos y sirve de ancla a la memoria, sobre todo de cara a la patrimonialización del lugar impulsada por UNESCO. La memoria de los descendientes de esclavos y la materialidad arqueológica pueden estructurar un relato alternativo, capaz de actualizar la narrativa histórica y patrimonial. Al reconocer el rol histórico de las comunidades afro hasta ahora invisibilizadas, la investigación se vuelve una herramienta para democratizar el pasado de esta joven nación. Es un pasado histórico breve, protagonizado por algunos colectivos humanos que a pesar de haber sido sacrificados actores del proceso de conformación nacional, permanecen aún ignorados en los textos educativos.

\section{Agradecimientos}

Este trabajo es fruto de las investigaciones que fueron realizadas en el marco del proyecto "Construcción participativa de la memoria de las comunidades afro descendientes de la frontera uruguayo-brasilera", financiado por la Comisión Sectorial de Extensión y Actividades en el Medio de la Universidad de la República del Uruguay. Tenemos un particular agradecimiento para las integrantes de la comisión directiva del Club Social Ansina (Castillos, Rocha), el club afro más antiguo del país, así como para los trabajadores de la Usina Cultural de Castillos (Rocha), del Ministerio de Educación y Cultura, especialmente Eduardo Pereyra, que fueron parte integrante del proyecto y que nos facilitaron contactos de informantes afros mayores a los que entrevistar. En este sentido queremos agradecer a las personas que nos dedicaron su tiempo para las entrevistas, y en concreto a María Lurdes Nunes da Silva y familia, a Almendra Terra y a Ramón Saravia. Asimismo los investigadores locales rochenses Profesor Jesús Perdomo, Néstor Rocha y Raúl Rocha nos facilitaron mucha información histórica, cartografía histórica e intercambiaron con nosotros sus constructivas opiniones sobre los afrouruguayos de este sector de frontera. Igualmente la mayor parte de los dueños, capataces y peones de las estancias que recorrimos fueron hospitalarios y nos 
facilitaron los trabajos en el interior de sus propiedades, brindándonos, además, mucha información muy relevante. De todos ellos queremos destacar al Sr. Nardone González y familia por su apoyo incondicional a la investigación. También nos gustaría destacar que gracias a los evaluadores anónimos el texto de este trabajo ha mejorado notablemente. Desde aquí nuestro más sincero agradecimiento por sus comentarios y críticas. 


\section{Referencias citadas}

" Andrade Lima, T. (1989). A tralha doméstica em meados do século XIX: reflexos da emergencia da pequena burguesía en Río de Janeiro. Dédalo, 1, 205-230.

" Barrios Pintos, A. (1967). De las vaquerías al alambrado: contribución a la historia rural uruguaya. Montevideo: Nuevo Mundo.

»Barrios Pintos, A. (2013). 400 años de Historia de la Ganadería en Uruguay. Montevideo: Ediciones Cruz del Sur.

" Borucki, A., Chagas, K. y Stalla, N. (2009). Esclavitud y trabajo: Un estudio sobre los afrodescendientes en la frontera uruguaya 1835-1855. Montevideo: CSIC. UdelaR.

» Borucki, A., Chagas, K. y Stalla, N. (2012). Rocha en tiempos de esclavitud y abolición. Amos, esclavos y morenos libres en el relato de la sociedad rochense. Revista Histórica Rochense, 1, http://www.revistahistoricarochense.com.uyl. (Acceso: 10 de abril, 2019).

» Bracco, R., Cabrera, L. y López Mazz, J. M. (200o). La prehistoria de las Tierras Bajas de la Cuenca de la Laguna Merín. En A. Durán y R. Bracco (Eds.), Arqueología de las tierras bajas (pp. 13-38). Montevideo: MEC.

»Chagas, K., Stalla, N. y Borucki, A. (2012). Oratorio de los Correa. En UNESCO (Ed.), Huellas e Identidades. Sitios de Memoria y culturas vivas de los afrodescendientes en Argentina, Paraguay y Uruguay (pp. 144-153). Montevideo: UNESCO.

"Criado-Boado, F. (2001). La Memoria y su huella. Sobre arqueología, patrimonio e identidad. Claves de Razón Práctica, 115, 36-43.

»Dabezies, J. M. (2019). Negotiating the Taskscape. Relocating Human - Environmental Relationships in Conservation Proposals around Palm Forests in Uruguay. Conservation and Society, 17(3), 236-249.

»Dabezies, J. M., De Souza, G. y Torena, D. (2017). Rethinking representations of the space in human-environmental relationships in Uruguay. Geoforum, 82, 189-199.

» Erbig, J. (2015). Imperial lines, indigenous lands: transforming territorialities of the Río de la Plata, 1680-1805. (Tesis Doctoral inédita), Universidad de North Carolina, Estados Unidos.

» Faría, S. (1998). A colonia em movimiento. Río de Janeiro: Nova Fronteira.

"Frega, A. (2010). Sitios de memoria de la esclavitud en el Uruguay. En UNESCO (Ed.), Sitios de memoria de la ruta del esclavo en Argentina, Paraguay y Uruguay. Villa Ocampo, Argentina 28 de octubre de 2009 (pp. 18-20). Montevideo: UNESCO.

» Funari, P. P. A. y Menezes, L. (2016). Historical Archaeology Outlook: A Latin American Perspective. Historical Archaeology, 50(3), 100-110.

" Gianotti, C. (2015). Paisajes sociales, monumentalidad y territorio en las tierras bajas de Uruguay. (Tesis Doctoral inédita), Universidad de Santiago de Compostela, España.

"Gomes Coelho, R. A. da G. (2017). Sensorial regime of "Second Slavery": landscape of enslavement in the Paraiba Valley (Río de Janeiro, Brasil). (Tesis Doctoral inédita), Universidad de Binghamton, Estados Unidos.

" Gómez, L. (2012). Huellas y paisajes de la ganadería en el territorio uruguayo. En Actas del $2^{\circ}$ Seminario de Paisajes Culturales Udelar/UPC (pp. 1-24). Montevideo: UdelaR.

"López Mazz, J. M. (2001). Las estructuras monticulares de las tierras bajas de Uruguay. Latin American Antiquity, 12, 231-251. 
» López Mazz, J. M. (2018). Sangre indígena en Uruguay. Memoria y ciudadanías post nacionales. Athenea Digital, 18(1), 181-201.

»López Mazz, J. M. y Bracco, D. (2010). Minuanos. Apuntes y notas para la historia y la arqueología del territorio Guenoa-Minuan (Indígenas de Uruguay, Argentina y Brasil). Montevideo: Linardi y Risso.

» Martínez Rovira, E. (1982). Entre el olvido y la memoria. Montevideo: UdelaR.

» Martins Farias, B. (2013). Geoglifos gauchos: um estudo sobre o troperismo e as cercas e currais de terra, pedra e plantas no sudoeste do Río Grande do Sul, Uruguai e Argentina. Pelotas: Gráficas Sem Rival.

» Menezes, L. F. (2019). Archaeology Also Dances: African Diaspora and Spiritual Practices at the BeefJerky Plantations in Pelotas, Southern Brazil. Trabajo presentado en el congreso Unfree Memories: Slavery, Materiality, and Public Space in the Atlantic World. New Jersey, Estados Unidos.

" Moraes, A. I. (2005). La gente, la tierra y el ganado en la Banda Oriental. Una revisión metodológica del saber establecido sobre la ocupación del territorio y la formación del paisaje agrario en el Uruguay. En Actas de las Segundas Jornadas de Historia Regional Comparada, [CD ROM]. Porto Alegre.

» Osório, E. (2004). Esclavos en la frontera: padrones de la esclavitud africana en Río Grande do Sul,1765-1825. En A. Bentacour, A. Borucki y A. Frega (Comps.), Estudios sobre la cultura afro rioplatense. Historia y Presente (pp.7-17). Montevideo: FHCE-UdelaR.

» Osório, E. (2014). Continuidades: estruturas agrárias e o trânsito na fronteira lusoespanhola na América meridional. Revista Complutense de Historia de América, 40, 93112.

»Palermo, E. D. (2005). Vecindad, frontera y esclavitud en el norte uruguayo y sur de Brasil. En UNESCO (Coord.), Memoria del simposio la Ruta del Esclavo en el Río de la Plata: su historia y sus consecuencias (pp. 90-114). Montevideo: UNESCO.

»Perdomo, J. (2012). La tropería más grande de la Historia. Revista Histórica Rochense, 1, http://www.revistahistoricarochense.com.uy/rhr-no-1/la-tropeada-mas-grande-de-lahistorial. (Acceso: 23 de marzo, 2018).

» Prado, C. (1945). Formaçao do Brasil contemporáneo. Río de Janeiro: Editora Brasiliense.

» Rocha, N. (2015). Club Social y Deportivo Ansina de Castillos. Bodas de Diamante. 19392014. Montevideo: Ministerio de Educación y Cultura.

» Saint Hilaire, A. ([1822] 1974). Viagem ao Río Grande do Sul. Sao Paulo: Universidad de Sao Paulo.

»Sala De Touron, L., Rodríguez, J. C. y De La Torre, N. (1968). Evolución económica de la Banda Oriental. Montevideo: Pueblos Unidos.

»Saldanha, J. (1998). Noticia sobre los Indios Minuanes. En Acosta y E. Lara (Ed), La Guerra de los Charrúas (pp. 248-252). Montevideo: Talleres de Loreto.

»South, S. (1977). Method and theory in Historical Archaeoloy. Nueva York: Academic Press.

» Tomich, D. W. (2004). Through the Prism of Slavery: Labor, Capital, and World Economy. Nueva York: Rowman and Littlefields.

»VVAA. (1966). Rocha en el centenario de Castillos. 1866-1966. Rocha: Intendencia Departamental de Rocha. 